\title{
Desenvolvimento Discente no Estágio em Estratégia Saúde da Família
}

\author{
Student Development during Clinical \\ Clerkships in Family Health Strategy
}

\section{PALAVRAS-CHAVE}

- Educação Baseada em Competências;

- Destreza Motora;

- Estágio Clínico;

- Saúde da Família;

- Educação Médica.

\section{KEYWORDS}

- Competency-Based Education;

- Motor Skills;

- Clinical Clerkship;

- Family Health;

- Medical Education.

\begin{abstract}
RESUMO
A formação do médico inclui, como etapa integrante da graduação, estágio curricular obrigatório de treinamento em serviço. O estágio em Estratégia Saúde da Família (ESF) foi implantado em 2007, no décimo período da Faculdade de Medicina da Universidade Federal de Alagoas, no primeiro ano do internato. Este estudo tem como objetivo analisar o desenvolvimento discente na Atenção Básica durante o estágio em ESF na percepção dos estudantes, estruturado como pesquisa qualitativa, com delineamento de estudo de caso. Os dados foram coletados por meio da técnica de Grupo Focal e analisados com a ferramenta de análise de conteúdo segundo Bardin. Emergiram quatro categorias: autonomia como reconhecimento de valor; relacionamento com usuários e profissionais do serviço; sentimento de frustração do estudante diante da realidade dos serviços de saúde; aquisição de competências e habilidades. Muitos dos fatores analisados foram necessários à composição de um quadro compreensivo quanto ao desenvolvimento de competências e habilidades específicas, previsto nas Diretrizes Curriculares Nacionais. Ao final, entendemos que cabe às escolas médicas dar continuidade às reflexões sobre o processo de formação dos graduandos.
\end{abstract}

\section{ABSTRACT}

As an integral stage of their degree, medical students complete an obligatory clinical clerkship. The Family Health Strategy (ESF) clerkship was implemented in January 2007 as part of the first year of students' internship, during their tenth semester at the Federal University of Alagoas School of Medicine (Famed-Ufal). This study aims to analyze students' development in Primary Health Care during their ESF internships, according to their own perceptions and by means of qualitative research and an explanatory case study. Data collection was conducted through Focus Groups and studied using the content analysis tool proposed by Bardin. Four categories emerged: autonomy as recognition of value; relationship with service users and professionals; medical students' frustration with the reality of the health services; and the acquisition of skills and abilities during the clerkship. Many of the factors analyzed were necessary for the composition of a comprehensive framework for the development of specific skills and abilities, as outlined in the National Curriculum Guidelines. By means of conclusion, we realize that it is medical schools' responsibility to build on the students' reflections on their degree course. 


\section{INTRODUÇÃO}

As Diretrizes Curriculares Nacionais (DCN) para os cursos de graduação em saúde apontam, como necessidade, a formação generalista, humanista, crítica e reflexiva dos profissionais das diversas áreas da saúde, como descrito em seu artigo terceiro ${ }^{1}$. $\mathrm{O}$ atual modelo hegemônico da formação médica tem origem nas modificações advindas do relatório Flexner, que foram implementadas nos Estados Unidos nas décadas de 1920 e 1930, expandindo-se por todo o mundo e implantadas no Brasil a partir de $1950^{2}$.

Atualmente, a maior parte dos profissionais de saúde em atividade traz uma formação hospitalar centrada nos procedimentos, exames e medicações adequados a cada patologia. Os estudos mostram que, nos dias de hoje, esse modelo já não mais atende às necessidades de formação de profissionais médicos generalistas. A educação médica no Brasil está em processo de transformação segundo as DCN do curso de graduação em Medicina, que orienta a concepção de novos projetos políticos pedagógicos e articula a integração entre o mundo do trabalho e a formação superior em saúde $\mathrm{e}^{1,3}$.

No início de 2007, concretizou-se a reforma da grade curricular no curso de Medicina da Ufal, que ampliou e implantou o internato de dois anos, visando ao treinamento em serviço, incluindo o estágio em Estratégia Saúde da Família (ESF), ofertado no décimo período, a princípio durante cinco meses. Esse processo foi viabilizado mediante convênio firmado entre a Ufal e a Prefeitura Municipal de Maceió, que permitiu o treinamento das Equipes de Saúde da Família e a inserção dos estudantes nas Unidades de Saúde da Família.

Exercendo a função de médico de uma das equipes de Saúde da Família do município de Maceió e, ainda, como docente da Famed-Ufal, atuando como coordenador e preceptor do estágio em ESF, percebi, por meio de observações empíricas de turmas anteriores, que, durante esse estágio, são oferecidas vivência e troca de experiências entre o ensino e o serviço, tendo como meta uma boa interação entre os estudantes e a equipe de saúde, proporcionando o desenvolvimento de competências e habilidades cognitivas e atitudinais.

Analisar esse processo através da percepção dos estudantes tem sua justificativa embasada na experiência de seis anos de implantação do estágio em ESF no curso de Medicina da Ufal.

Os diferenciais do modelo assistencial propostos pela Estratégia Saúde da Família, confrontados com referenciais do desenvolvimento referidos pelos discentes, poderão fornecer respostas à principal formulação desta pesquisa: como os discentes, no décimo período do curso de Medicina da Ufal, percebem seu desenvolvimento durante o estágio em ESF?
Este estudo visa contribuir para o desenvolvimento curricular da Famed-Ufal, em especial com os aspectos da formação relacionados à integração ensino-serviço, e tem como objetivo analisar o desenvolvimento no estágio em Estratégia Saúde da Família, na percepção do discente do curso de Medicina da Ufal.

\section{O INTERNATO NO CURSO DE MEDICINA DA UFAL}

A Faculdade de Medicina de Alagoas foi fundada em 3 de maio de 1950 e, em janeiro de 1951, teve autorizado seu funcionamento e primeiro vestibular ${ }^{4}$.

Em 1991, aconteceu a mudança mais significativa no ensino médico da Ufal, por ocasião da elaboração do projeto pedagógico dessa universidade, momento em que a direção do Centro de Ciências da Saúde (CSAU) definiu o perfil do formando como sendo capaz de interferir na realidade sanitária, tendo como referência o Sistema Único de Saúde (SUS) e adquirindo conhecimento suficiente para atuar no mercado de trabalho como generalista ${ }^{4}$.

A partir de 2001, com a criação do Núcleo de Ensino Médico da Ufal (Nemed), conseguiu-se construir um "Projeto de Reestruturação do Curso Médico", aprovado pelo Colegiado do curso em 2002. Entre julho de 2004 e outubro de 2005, esse Colegiado deliberou sobre um currículo de transição necessário à implantação do novo com propostas originadas em cada departamento e submetidas à reunião plenária do curso com docentes, discentes e técnicos ${ }^{4}$.

Desde então, a ênfase na aquisição de conhecimentos teóricos ficou concentrada até o oitavo período, sendo os últimos quatro períodos realizados em regime de internato. O período do internato foi estruturado para ser desenvolvido em dois anos e sua inserção no serviço nos cenários de práticas disponíveis após discussão em várias reuniões, visando a uma uniformidade de interesses na formação.

Nessa perspectiva, o internato tem como objetivo geral: "propiciar formação, de natureza geral, com conhecimentos, habilidades e posturas necessárias ao diagnóstico, tratamento, prevenção e promoção nas situações de maior prevalência e relevância no exercício da prática médica ${ }^{4 \prime \prime}$ (p. 37).

Os estágios que compõem o internato ocorrem em serviços próprios ou conveniados e com supervisão direta dos docentes da própria faculdade ou médicos/preceptores do serviço, incluindo as áreas de Clínica Médica, Cirurgia, Ginecologia-Obstetrícia, Pediatria e Saúde Coletiva, priorizando a Atenção Básica no primeiro ano e atividades no segundo e no terceiro níveis de atenção em cada área, durante o segundo ano, além do estágio rural obrigatório ${ }^{1,4}$. 
A proposta de inserção dos discentes nas Unidades Básicas de Saúde visa a uma oportunidade única de vivência da clínica na Atenção Básica, ainda sob supervisão, permitindo aos discentes ter uma visão do papel do médico na Estratégia Saúde da Família, conforme preconizado pelo SUS4

Assim sendo, os espaços formativos devem ser pactuados entre ensino-serviço e utilizar unidades e equipamentos próprios da Atenção Primária à Saúde (APS), preferencialmente em Unidades de Saúde da Família, integradas à rede municipal ${ }^{5}$.

\section{A inserção do estágio em Estratégia Saúde da Família}

A história do Programa Saúde da Família (PSF) teve início em 1991, quando o Ministério da Saúde (MS) formulou o Programa de Agentes Comunitários de Saúde (Pacs). Por volta de 1993, o MS iniciou a implementação do PSF no Brasil, por intermédio da Portaria nº 692. Em janeiro de 1994, formaram-se as primeiras equipes de Saúde da Família, para reorganizar a Atenção Primária à Saúde em nosso país ${ }^{6}$.

Com a publicação da Política Nacional de Atenção Básica aprovada pela Portaria no 648/GM, de 28 de março de 2006, o PSF passou a ser chamado de Estratégia de Saúde da Família, visando à reorganização da APS no Brasil7.

Com a denominação de Internato em Atenção Básica V PSF, o estágio em Estratégia Saúde da Família foi implantado na Famed-Ufal em janeiro de 2007, sendo ofertado no primeiro ano do internato, durante o décimo período do curso, com carga horária de 560 horas, por 20 semanas consecutivas, com 40 estudantes por turma.

A partir de 2010, o estágio passou a ter a denominação de Clínica Médica 1, para fins de registro como disciplina no sistema acadêmico da Ufal, com duração de 12 semanas, carga horária semanal de 36 horas, 20 estudantes por turma, e continuou sendo ofertado no décimo período do curso.

Os estudantes são distribuídos entre as dez Unidades de Saúde da Família (USF) pertencentes à rede pública municipal conveniada com a Ufal. A quantidade de estudantes por USF depende de sua estrutura física, sendo, em média, dois estudantes para cada médico-preceptor.

O estágio na rede básica precisa ser ordenado, tanto por razões pedagógicas quanto de funcionamento dos serviços, em pequenos grupos de alunos, com supervisão e acompanhamento de professores e de tutores ou colaboradores escolhidos entre as equipes da APS 4 .

Durante o período deste estudo, o estágio em ESF contava com 12 preceptoras médicas da Estratégia Saúde da Família de Maceió, que atuavam com a função de orientar e avaliar a aprendizagem discente baseada nas competências/habilidades preconizadas nas DCN.
Ao término do estágio, o discente é avaliado, por seu preceptor-médico e por um docente supervisor de campo, mediante a utilização de métodos formativos e, também, com métodos somativos em encontros semanais de estudo, os quais são contextualizados e adequados ao desenvolvimento das competências em APS 5 .

\section{Competências e Habilidades Definidas para os Cursos de Medicina}

O termo "competência" surgiu no início da década de 1970, no âmbito empresarial, designando as características de uma pessoa capaz de realizar uma tarefa de forma eficiente. No âmbito da educação escolar, a competência "deve identificar o que qualquer pessoa necessita para responder aos problemas aos quais será exposta ao longo da vida"8 (p.11).

"Habilidade" geralmente é usada para designar a capacidade de realizar atos cognitivos e/ou práticos de alta complexidade (raciocínio clínico, punção venosa central, exame físico, etc. $)^{9}$.

A descrição detalhada das competências e habilidades gerais e específicas constantes da formação do médico encontra-se na Resolução CNE/CES 4/2001, que instituiu as DCN para os cursos de Medicina, em seus artigos quarto e quinto, bem como no PPC de Medicina da Ufal e nas Diretrizes para o ensino na Atenção Primária à Saúde na graduação em Medicina ${ }^{1,4,5}$.

Baseando-se nesses documentos norteadores, este estudo analisou o desenvolvimento discente de valores, sentimentos, competências e habilidades inter-relacionados, incorporando-os à abordagem nas dimensões individual, familiar e comunitária.

\section{PERCURSO METODOLÓGICO}

\section{Tipo de Pesquisa}

O presente estudo foi estruturado como uma pesquisa qualitativa, estudo de caso do tipo exploratório, que responde às questões "como" e "por quê". Existem dois tipos de estudos de caso: caso único e casos múltiplos. Elegemos o caso único pela justificativa de ser representativo ou típico, e com o objetivo de captar as circunstâncias e as condições de uma situação diária ou de um lugar-comum ${ }^{10}$.

\section{Local e Sujeitos do Estudo}

Foram estudados dez discentes, que cursavam o décimo período do curso de Medicina da Famed-Ufal, sorteados aleatoriamente para compor a amostra do Grupo Focal (GF).

Os critérios de inclusão foram estar cursando o décimo período do curso de Medicina e já ter realizado o estágio em Estratégia Saúde da Família. Para critérios de exclusão, alunos 
que cursavam os demais períodos; com matrículas fechadas ou não regularizadas; afastados por motivo de doença.

\section{Coleta dos Dados}

Usamos para a coleta de dados a técnica de Grupo Focal, realizada em junho de 2012, com duração de uma hora e 42 minutos, sendo retiradas todas as dúvidas sobre o estudo em momento anterior ao início do grupo, quando também foi lido e assinado o TCLE.

O grupo focal é um tipo de entrevista em profundidade, realizada em grupo, que tem por objetivo coletar informações por meio do diálogo acerca de um tema específico. Ela possui seis funções a serem desempenhadas durante sua execução: o mediador é o responsável pelo início dos trabalhos, pela motivação do grupo, pelo desenvolvimento e pela conclusão dos debates; o relator anota as falas e também registra a linguagem não verbal; o observador tem como função analisar e avaliar o processo de condução do GF; o operador de gravações executa a gravação integral dos debates; o digitador tem como atribuição transcrever todos os dados na íntegra ${ }^{11}$. Nessa fase, o pesquisador participou no papel de observador.

Para manter o sigilo, os discentes escolheram codinomes, que foram utilizados durante os debates e nas transcrições de suas falas. Visando contribuir para um clima de confiança e confraternização, foi servido um lanche como forma de acolhimento ao grupo.

Foi utilizado um roteiro com quatro questões-chave baseadas nas competências e nas habilidades específicas, elencadas nas DCN do curso de graduação em Medicina, em seu artigo quinto.

\section{Análise dos Dados}

Os dados obtidos no grupo focal foram transcritos, digitados e analisados pelo autor, seguindo a técnica de análise de conteúdo temática, segundo Bardin ${ }^{12}$. Após a transcrição dos dados, foi realizada uma leitura por três pessoas diferentes, para consolidação das categorias surgidas. A análise dos dados permitiu construir quatro categorias.

\section{Aspectos Éticos}

Esta pesquisa foi aprovada pelo CEP do Centro Universitário Cesmac, protocolo 1313/12.

\section{RESULTADOS E DISCUSSÃO}

A análise dos dados possibilitou identificar quatro categorias: autonomia como reconhecimento de valor; relacionamento com usuários e profissionais do serviço; sentimento de frustração do estudante de Medicina diante da realidade dos serviços de saúde; aquisição de competências e habilidades durante o estágio. Faremos, a seguir, uma reflexão sobre os consensos temáticos que emergiram do GF, com base nos referenciais teóricos propostos.

\section{Categoria 1: Autonomia como Reconhecimento de Valor}

Considerando-se aspectos éticos e morais, encontramos, relacionada a esta categoria, a liberdade moral do indivíduo, que, pelo esforço de suas próprias reflexões, possibilita a si mesmo os seus princípios de ação. Isso não significa viver sem regras, mas as que são obedecidas são as escolhidas. Portanto, o respeito à autonomia e à dignidade de cada um é um imperativo ético e não um favor que podemos ou não conceder uns aos outros $^{13}$.

No âmbito da educação, o debate moderno em torno do tema remonta ao processo dialógico de ensinar contido na filosofia grega, que preconizava a capacidade do educando de buscar respostas às suas próprias perguntas, exercitando, portanto, sua formação autônoma ${ }^{14}$, constatação que encontramos em João e Neto:

[...] a nossa médica era sempre muito solícita e ela dava muita autonomia pra gente [...] deixava a gente atender e tirar as dúvidas com ela [...]". (João)

"Então como eu estou com o paciente, eu tenho que dar o diagnóstico, depois tenho que chegar pra ela e passar o caso e dar minha conduta pra ver se ela concorda". (Neto)

Neste estudo, verificamos que o estudante deseja ser reconhecido como alguém com conhecimentos e habilidades prévios, resultado de competências alcançadas em estágios anteriores, sendo, portanto, capaz de formular diagnósticos e condutas terapêuticas. Isto pode ser traduzido como autonomia, que foi encontrada em falas como as seguintes:

\footnotetext{
"Eu mesmo quero dar seguimento do caso. Se ele chegar com o diagnóstico, com exame, eu dou o diagnóstico e trato". (Neto)

"Porque eu consegui trazer a paciente com insuficiência cardíaca, trouxe pra cárdio e a gente discutiu, conversou, manejou a paciente, e a paciente em uma semana teve uma melhora significativa". (Tavares)
}

A autonomia é também percebida como algo acrescido, capaz de conferir segurança ao exercício profissional futuro:

"[...] mais adiante, quando a gente já estiver formado, a gente saiba conduzir o local, porque é essencial que o médico tome a frente do seu local de trabalho". (Rocha) 
Existem limites à autonomia médica quando os profissionais médicos ficam limitados à aplicação de saberes preestabelecidos e ao uso de tecnologias investigativas ${ }^{15}$. Essa limitação da autonomia médica, já despertada nos estudantes, foi destacada em alguns trechos do GF.

"Então você tem que atender aquela demanda de qualquer forma". (Santos)

"[...] nossas condutas, que devem ser regradas conforme se preconizam nas diretrizes do Ministério da Saúde [...]" (Nascimento)

Acreditamos que o desenvolvimento da autonomia já se inicia no primeiro semestre do curso, quando os estudantes são estimulados para o processo de aprendizagem durante os grupos tutoriais. A metodologia da tutoria tem seus fundamentos na Aprendizagem Baseada em Problemas (ABP, derivada do original inglês Problem-Based Learning - PBL), que surgiu no Canadá, na década de 1960. No Brasil, sua utilização integral ainda é muito restrita ${ }^{16}$.

\section{Categoria 2: Relacionamento com usuários e profissionais do serviço}

Esta categoria retrata o relacionamento discente com o outro, na construção de suas competências e habilidades e no desenvolvimento de uma postura ética. Identifica-se, também, através da mesma, que o cenário de prática do estágio em ESF possibilita a criação de vínculos, quer seja com os usuários e suas famílias, quer seja com os profissionais do serviço de saúde.

Neste estudo, verificamos que os estudantes demonstraram atitudes éticas em desenvolvimento embasadas em práticas cotidianas em comunidades carentes, cumprindo um dos objetivos propostos pelas Diretrizes para o ensino na APS: "desenvolver e aplicar a consulta do médico de família e comunidade para promover uma eficaz relação médico-paciente, com respeito pela autonomia deste ${ }^{5 \prime \prime}$ (p. 145), o que vemos revelado na fala de Nascimento:

"[...] prover os recursos necessários que ele tenha ao alcance dele para prover a melhora daquele paciente nas necessidades que ele está precisando no momento".

Entre as atividades propostas para os estudantes no estágio aqui abordado, encontra-se a visita domiciliar. Essa atividade se caracteriza por dar assistência às famílias e à comunidade, entendida como "entidades influenciadoras no processo de adoecer dos indivíduos ${ }^{17 "}$ (p. 1104), favorecendo o estabelecimento de relacionamento e vínculo. Os estudantes fizeram uma avaliação positiva sobre a visita domiciliar, que julgaram ser o novo:

"[...] na visita domiciliar [...] você tem mais tempo de conversar com o paciente [...]" (Tavares)

"[...] a gente tinha esse tempo de conversar bem com o paciente [...] conversar um pouco da parte psicossocial também com o paciente". (Pereira)

Também encontramos relatos positivos quanto ao relacionamento com os membros da equipe de saúde em que os estudantes foram lotados, como forma de se adaptar à organização do sistema:

"[...] esse manejo que você tem que ter com os outros profissionais do local, e é essencial você enfrentar essas dificuldades [...]" (Rocha)

"Lá o tratamento é exemplar entre todos os funcionários que trabalham: agente de saúde, técnico de enfermagem, dentista, médicos". (Nascimento)

No estágio em ESF, o aprofundamento do vínculo ou a manutenção da superficialidade desse relacionamento são reconhecidos como dependentes do perfil do preceptor e do discente. Apesar de um corporativismo implícito inerente à categoria médica, alguns estudantes relataram o enfrentamento de dificuldades de relacionamento com seus preceptores, que serão seus futuros pares em termos de profissão.

\footnotetext{
“Não é todo médico que tem a capacidade de saber lidar com acadêmico. Ele não sabe como conduzir uma consulta médica voltada pro acadêmico". (Neto)

"Se eu for prum posto onde o serviço não funciona, o médico não é comprometido, você não aprende". (Neto)
}

Para que aconteça o desenvolvimento da competência de manter um bom relacionamento com usuários e profissionais nos serviços de saúde, os estudantes precisam exibir uma postura comunicativa e disponibilidade para trabalhar em equipe multiprofissional. A interação do estudante com os profissionais de saúde está prevista nas DCN, como sendo relações "compatíveis com seu grau de autonomia, que se consolida na

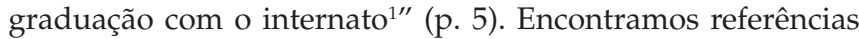
incipientes sobre o trabalho interdisciplinar nas falas de Neto e Rocha:

\footnotetext{
"Tava médico, a enfermeira; aí nós acadêmicos também".
} 
"É... e eu acho que faz parte da nossa caminhada você saber lidar com o paciente e saber lidar também com os profissionais do local de trabalho".

Permeando os depoimentos de bom relacionamento com a maioria dos profissionais do serviço e algumas dificuldades pontuais em relação ao contato com os preceptores, encontramos ainda a negação dos estudantes ao aprendizado com as categorias não médicas, numa rejeição ao trabalho interdisciplinar:

"E até porque a citologia não é um ato da enfermagem, $e$ acabamos atendendo uma coisa errada. Não desmerecendo nenhum profissional, mas não devia ser feito". (Gabriela)

"Não é necessário toda semana ir na farmácia pra ver como é que eles vão liberar medicação". (Gabriela)

Acreditamos que a metodologia tutorial, assim como contribui para o desenvolvimento da autonomia, também o faz quanto ao desenvolvimento da competência/habilidade do estudante em se relacionar com o outro e criar vínculos, pois são pontos-chave trabalhados durante os grupos tutoriais ${ }^{16,18}$. Encontramos uma referência positiva sobre esta metodologia na fala de Pereira:

\footnotetext{
"Eu acho que vale muito mais a gente estar discutindo, todo mundo hoje tem conteúdo, tem..., sabe onde achar, a gente já está num nível bom, a época de tutoria ensinou isso, e acho bem mais proveitoso".
}

Observamos que os estudantes desenvolveram a habilidade de saber escutar as necessidades dos pacientes e, concomitantemente, atitudes prudentes e tolerantes diante das queixas encontradas, subsidiando a construção de uma relação profissional ética, embasada no respeito ao outro, como princípio ético ${ }^{19}$.

"[...] no essencial é você conversar com o seu paciente, saber da situação dele familiar no momento, se ele tá passando por algum problema, e a partir daí você tomar a sua conduta clínica". (Rocha)

"Tá acontecendo alguma coisa de diferente na sua casa pra essa pressão ter subido assim de repente, não?" (Maria)

No material discursivo, sobressai o reconhecimento do desenvolvimento das competências, habilidades e atitudes nas relações entre os estudantes com os profissionais do serviço de saúde e os usuários, contribuindo para uma incipiente criação de vínculos, numa demonstração de aplicação prática de sua autonomia.

\section{Categoria 3: Sentimento de Frustração do Estudante de Medicina diante da Realidade dos Serviços de Saúde}

Durante o estágio em ESF, os estudantes permanecem numa UBS e mantêm contato frequente com a mesma equipe de profissionais. Isto faz com que eles desenvolvam maior aproximação com a preceptoria, o que possibilita a expressão de suas angústias. Esse fato foi observado na fala de Tavares:

"[...] é, eu acho que o médico fica muito incapacitado e acho que até muitas vezes por negligência, porque ele poderia fazer até um pouco mais, o médico da Estratégia".

Verificamos, na prática do dia a dia, como docente/ preceptor, que eles expressam, com maior frequência e mais veemência, as suas críticas e sugestões entre seus pares. No momento em que eles se sentem seguros da possibilidade de sua fala (fato que aconteceu quando da oportunidade de se expressarem neste estudo), é possível detectarmos em suas falas o sentimento de frustração diante das dificuldades inerentes à rede de serviço. Como vemos na fala de Neto:

\footnotetext{
"Uns postos funcionam muito bem, outros não funcionam. Se eu for prum posto onde o serviço não funciona, o médico não é comprometido, você não aprende. [...] a preceptora tinha um grande, um elevado grau de absenteísmo no posto, faltava muito e sem motivo [...]".
}

A frustração apareceu também quando os estudantes levantaram o problema da falta de capacitação dos médicos para atuação como preceptores ao se implantar o estágio em ESF nos serviços conveniados com a rede de saúde municipal.
"[...] entendo uma diferença muito grande entre médico e preceptor. Normalmente, nos postos, pelo que eu percebo, existem médicos, não preceptor. (...) Ele tem que ter o preparo pra ser preceptor. Noventa por cento apenas são médicos que acabam que..., por vontade, normalmente são por boa von- tade. Quase todos têm boa vontade de ensinar, mas não têm preparo pra preceptoria". (Neto)

A função do preceptor é entendida como um mediador entre a teoria e a prática na formação dos estudantes estagiários no serviço ${ }^{20}$. Neste estudo, os estudantes discutiram a capacitação e a formação do preceptor.

\footnotetext{
"A universidade tem que formar o preceptor que tá lá no posto. Eu acho isso: tem que ter um curso de capacitação pros preceptores do PSF". (Neto)
}

Era de se supor que os médicos da rede que exercem a função de preceptoria se comportassem como professores, 
mas não foi isso que encontramos neste estudo. Os estudantes demonstram maturidade quando se colocam na posição de futuros profissionais e analisam a realidade que vivenciaram no estágio em ESF, denotando uma preocupação com a atuação dos atuais médicos/preceptores da rede conveniada.

“O PSF, queira ou não queira, é uma opção, a gente vai se formar daqui a um ano, e é uma opção, uma opção bem paga, fácil, fácil... É fácil conduzir, conduzir e sem preparo, atualização. (Santos)

Observamos que os estudantes expressaram sentimento de impotência diante das situações cotidianas nas quais não têm poder de resolutividade, mostrando-se frustrados quanto à ineficiência do serviço de saúde.

"É bem frustrante você tá nessa situação, sabendo que não pode mudar porque é o protocolo, e não adianta discutir. Assim, sinceramente, a gente tava acostumado com outro nível de discussão. Não sei se é isso que o Silva chama de medicina rasteira, mas que com certeza é frustrante, é". (Pereira)

"Eu ficava triste quando a gente, na conduta, escrevia lá: encaminhado para avaliação de tal especialidade; e aí entregava o paciente, e o paciente saía de lá, e a gente sabia que aquele paciente ia fazer uma peregrinação pra tentar uma consulta e aquela enfermidade que a gente suspeitou que ele já tinha provavelmente não ia ser tratada ou ia ficar sendo subtratada por nós". (Nascimento)

Apesar das dificuldades operacionais dos serviços da APS, preconiza-se que o ensino de cuidados básicos na graduação deve fazer parte das competências dos profissionais em formação ${ }^{20}$. Observou-se, nos diálogos dos estudantes, o imaginário negativo sobre a atuação na Atenção Primária.

"O que eu achei, assim, que durante o estágio não valeu a pena foi, no caso, o acompanhamento nas salas de imunização ou a pré-consulta. [...] Atendendo pressão, medindo e pesando 20, 30 pacientes que vão pra consulta não acrescentou em nada". (Gabriela)

\footnotetext{
"Eu penso que o momento de tá acompanhando uma pré-consulta, eu posso tá fazendo uma visita, eu posso tá até discutindo um caso, eu posso tá acompanhando mais consultas". (Neto)
}

Muitos desses fatores aqui analisados como sentimentos de frustração são necessários à composição de um quadro compreensivo quanto ao desenvolvimento de competências e habilidades específicas, previstas nas DCNs, no tocante à análise crítica por parte dos estudantes em relação à dinâmica do mercado de trabalho e sua atuação em equipe multiprofissional, visando à efetivação de uma boa comunicação com seus colegas de trabalho como suporte para um bom relacionamento interpessoal.

\section{Categoria 4: Aquisição de Competências e Habilidades Durante o Estágio}

O termo habilidade geralmente é usado para designar a "capacidade de realizar atos cognitivos e/ou práticos de alta complexidade", enquanto "competência tem caráter mais amplo e inclui conhecimento, atitudes, habilidades cognitivas e práticas em um caráter mais holístico" (p. 6). Nas dimensões da competência, estão incluídas, também, as funções de relacionamento, integrativa, afetiva e moral.

Partindo desse conceito, analisamos as falas discentes e encontramos que, na sua concepção, habilidade é:

\begin{abstract}
"características, aptidões e atitudes necessárias que um profissional de diversas, de qualquer área, ele deve ter para corresponder, é, fazer cumprir o objetivo para o qual ele foi formado [...]". (Nascimento)
\end{abstract}

\section{"[...] basicamente que é conhecimento e técnica". (Joana)}

O estágio em ESF prevê a inserção dos estudantes nas equipes de trabalho para vivenciar os momentos de planejamento, visando ao acompanhamento do indivíduo, da família e da comunidade. Apesar disso, percebemos que eles identificaram um maior número de competências relacionadas à abordagem individual, que no estágio em ESF também predomina e é percebida e valorizada quando identificam o estabelecimento do primeiro contato com os pacientes, lidando com problemas não selecionados e indiferenciados ${ }^{5}$, como demonstram as seguintes falas:

"[...] você fica com aquela sensação de repetição e que faz com que você adquira uma segurança pra atender [...]". (Tavares)

"Isso é uma coisa que você só aprende vivenciando a prática, conversando, e no dia a dia atendendo vários e vários pacientes". (João)

Apesar da percepção, por parte dos estudantes, de que o foco maior de atenção é a abordagem individual, eles conse- 
guem fazer a correlação entre a tomada de decisão e os determinantes sociais, culturais e psicológicos do indivíduo, considerando a relação custo-benefício nas decisões médicas ${ }^{1,5}$.

"Então acho que a habilidade nesse momento que a gente desenvolveu é de fazer a opção pro paciente, dele ter direito a fazer a compra do medicamento melhor pra ele no momento ou utilizar o do posto". (Rocha)

"Eu acho que você adquire a habilidade de saber que grande parte daquelas patologias é decorrente do nível social que a pessoa vive, do ambiente socioeconômico que o indivíduo vive". (Tavares)

Eles conseguiram, também, relacionar os processos específicos de decisão com a prevalência e a incidência das doenças na comunidade $\mathrm{e}^{1,5,8}$.

"[...] observei uma incidência muito grande de depressão nos pacientes do nosso posto. [...] A gente criou um banco de dados com os nossos atendimentos, e a quarta ou quinta queixa mais importante era depressão". (Pereira)

"[...] o que eu vi de mulheres e mulheres com doenças reumáticas e psiquiátricas [...]". (Silva)

Ainda aparece, em suas falas, a utilização das evidências científicas como ferramenta e suporte, singularizando o processo de atendimento ${ }^{1,5}$, mesmo que em forma de crítica ao modelo assistencial, como destacamos a seguir.

"No nosso posto tinha protocolo pra diabetes, hipertensão, gestação, que era mais ou menos seguido [...] Pra mim o protocolo é uma coisa pra ser seguida, com certeza, mas ele é um mínimo, você tá fazendo o mínimo". (Pereira)

"[...] a gente deve ter muito cuidado, prestar muita atenção, tanto em nossas condutas, que devem ser regradas conforme se preconizam nas diretrizes do Ministério da Saúde [...]". (Nascimento)

Também sobressaiu a promoção da saúde e do bem-es$\operatorname{tar}^{1,5}$, no âmbito individual, quando os estudantes destacaram a aplicação de estratégias de promoção da saúde e prevenção da doença.

"A gente na nossa conduta orientava mudança de hábitos de vida, estilo de vida, ingestão de sódio, exercício [...]". (Nascimento)
"Perto do nosso posto tem um local pra fazer exercício físico, não é um ginásio, pertencente à associação de moradores". (Pereira)

A valorização do método clínico, a utilização de procedimentos diagnósticos e terapêuticos, bem como a realização do exame físico ${ }^{1,5}$, como parte integrante da rotina de atendimento do indivíduo, foram percebidas na fala de alguns estudantes:

"[...] manusear uma consulta e ter o manejo [...] pensar na dosagem das medicações que são mais utilizadas na Atenção Primária [...]". (Tavares)

"[...] eu atendia devagar, dava pra fazer várias coisas. Eu fazia exame físico". (Neto)

Finalizando o enfoque sobre a abordagem individual quanto à atuação no sistema hierarquizado de saúde, obedecendo aos princípios técnicos e éticos de referência e contrarreferência ${ }^{1,5}$, a estudante Maria apontou a dificuldade do sistema de saúde em atender à demanda:

"Algumas vezes indicava pro especialista, e demorava muito pra conseguir, mas no final sempre conseguia".

Embora os posicionamentos anteriores destaquem o foco do atendimento no indivíduo, houve referências às relações intrafamiliares no processo de saúde e adoecimento ${ }^{8}$.

"Eu acho que isso não é essencial, o essencial é você conversar com o seu paciente, saber da situação dele familiar no momento, se ele tá passando por algum problema, e a partir daí você tomar a sua conduta clínica". (Rocha)

Por fim, alguns estudantes relataram atividades voltadas à abordagem comunitária ${ }^{4,5}$, quando referem participação em atividades de educação popular em saúde.

"A gente participou de um tipo de discussão sobre sexualidade com adolescentes". (Neto)

\footnotetext{
"Nossa comunidade também tinha outros grupos. Tinha grupo de crochê, grupo de discussão de mesa-redonda com jovens". (Pereira)
}

$\mathrm{Na}$ contramão dessas constatações sobre o desenvolvimento de competências e habilidades previstas nas diretrizes para o ensino na APS e relacionando-as à discussão da categoria anterior, sobre o sentimento de frustração dos estudantes, 
percebemos que alguns deles não conseguem enxergar esse desenvolvimento, ao menos não por completo, como constatamos nos trechos seguintes:

Uns postos funcionam muito bem, outros não funcionam. Se eu for prum posto onde o serviço não funciona, o médico não é comprometido, você não aprende. [...] Não é todo médico que tem a capacidade de saber lidar com acadêmico. (Neto)

Eu penso que o momento de tá acompanhando uma pré-consulta, eu posso tá fazendo uma visita, eu posso tá até discutindo um caso, eu posso tá acompanhando mais consultas. (Neto)

Com base nos resultados advindos da nossa discussão, consideramos a comunicação um fator importante para o desenvolvimento discente. A comunicação afirma ou não as relações entre as pessoas que se comunicam, sendo o diálogo não apenas uma tática para fazer dos estudantes amigos, mas algo que faz parte dos próprios seres humanos, significando uma "tensão permanente entre a autoridade e a liberdade ${ }^{21 "}$ (p. 67).

\section{CONSIDERAÇÕES FINAIS}

Consideramos que a questão central deste estudo foi contemplada, na medida em que os estudantes revelaram percepções sobre seu desenvolvimento durante o estágio em Estratégia Saúde da Família, como parte integrante do internato do curso de Medicina da Ufal, além de contribuir com a "formação crítica e reflexiva", prevista nas DCN.

O material discursivo revelou que a comunicação ocorreu entre estudantes profissionais e usuários, apesar das limitações de relacionamento citadas por alguns, e propiciou a criação de vínculos e o desenvolvimento da autonomia discente, importantes para o exercício futuro da profissão médica.

Apesar disso, identificamos a frustração do estudante diante da constatação da limitação da autonomia médica e das dificuldades enfrentadas nos relacionamentos com os profissionais do serviço, incluindo seus futuros pares. Todavia, entendemos que esses sentimentos de frustração foram necessários à composição de um quadro compreensivo quanto ao desenvolvimento discente de competências e habilidades específicas, previstas nas DCN, ou seja, a análise crítica do mercado de trabalho, onde, em breve, a maioria dos recém-graduados estará atuando como profissionais médicos.

A categoria temática sobre aquisição de competências e habilidades durante o estágio evidenciou o desenvolvimento discente e mostrou que os alunos se percebem como futuros médicos, agentes de transformação, e não meros agentes passivos de reprodução técnica especializada ou de protocolos.
Ao final deste estudo, entendemos que não podemos fazer generalizações com base nos resultados encontrados. No entanto, temos a compreensão de que cabe às escolas médicas dar continuidade às reflexões sobre o processo de formação de seus graduandos, como também dar suporte à educação permanente dos médicos/preceptores da rede de saúde conveniada à Instituição de Ensino Superior.

\section{REFERÊNCIAS}

1. Brasil. Ministério da Educação. Conselho Nacional de Educação. Diretrizes Curriculares Nacionais do Curso de Graduação de Medicina.Câmara de Educação Superior. Resolução CNE/CES 4/2001. Diário Oficial da União, Brasília, 9 de novembro de 2001. Seção 1, p. 38.

2. Miranda JFA. Estudo do Impacto da Adoção da Estratégia de Saúde da Família no Internato Médico [dissertação]. Petrópolis (RJ): Universidade Católica de Petrópolis; 2002.

3. Cunha GT. A construção da clínica ampliada na Atenção Básica. Campinas; 2004. Mestrado [Dissertação] - Universidade Estadual de Campinas.

4. Universidade Federal de Alagoas (UFAL). Projeto Pedagógico do Curso de Medicina. Maceió, 2006.

5. Demarzo MMP, Almeida RCC, Marins JJN, Trindade TG, Anderson MIP, Stein AT, et al. Diretrizes para o ensino na atenção primária à saúde na graduação em medicina. Rev bras educ med. [online]. 2012;36(1):143-148. [acessado em 06 mar. 2013]. Disponível em: http:/ / www.scielo.br/pdf/ rbem/v36n1/a20v36n1.pdf

6. Santana ML, Carmagnani MI. Programa Saúde da Família no Brasil: Um Enfoque Sobre Seus Pressupostos Básicos, Operacionalização e Vantagens. Saúde e Sociedade 2001;10(1):33-53 [acessado em 31 mar. 2013]. Disponível em: www.scielo.br/pdf/sausoc/v10n1/04.pdf

7. Brasil. Ministério da Saúde. Secretaria de Atenção à Saúde. Departamento de Atenção Básica. Política Nacional de Atenção Básica. Brasília: Ministério da Saúde; 2006.

8. Zabala A, Arnau L. Como aprender e ensinar competências. Porto Alegre: Artmed; 2010.

9. Bollela VR, Machado JLM. Internato baseado em competências: "bridgingthe gaps". 1.ed. Belo Horizonte: Editora MedVance; 2010.

10. Yin RK. Estudo de caso: planejamento e métodos. Tradução Ana Thorell; revisão técnica Cláudio Damacena. 4.ed. - Poto Alegre: Bookman; 2010.

11. Cruz Neto O, Moreira MR, Sucena LFM. Grupos Focais e Pesquisa Social Qualitativa: o debate orientado como técnica de investigação. XIII Encontro da Associação Brasileira de Estudos Populacionais. Ouro Preto, MG; 2002. 
12. Bardin L. Análise de conteúdo. Lisboa: Edições 70; 1977.

13. Freire P. Pedagogia da autonomia: saberes necessários à prática educativa. São Paulo: Paz e Terra; 2011.

14. Martins AM. Autonomia e educação: a trajetória de um conceito. Cadernos de Pesquisa. 2002;(115):207-232. [acessado em 22 mar. 2013]. Disponível em: www.scielo.br/ pdf/cp/n115/a09n115

15. Azevedo Júnior R. A autonomia do médico. Revista Ser Médico 2011; 14(54). [acessado em 06 abr. 2013]. Disponível em: www.cremesp.org.br/library/modulos/flipbook/ revista/54/files/assets/downloads/publication.pdf

16. Mamede S,org. Aprendizagem baseada em problemas: anatomia de uma nova abordagem educacional. Fortaleza: Hucitec; 2001.

17. Albuquerque ABB, Bosi MLM. Visita domiciliar no âmbito da Estratégia Saúde da Família: percepções de usuários no Município de Fortaleza, Ceará, Brasil. Cad. Saúde Pública [online]. 2009;25(5):1103-1112. [acessado em 03 abr. 2013]. Disponível em: http://www.scielo.br/pdf/csp/ v25n5/17.pdf

18. Donoff M, Lawrence K, Allen T, Brailovsky C, Crichton T, Bethune C, Laughlin T, Wetmore S. Defining competency-based evaluation objectives in family medicin: professionalism. CanFamPhysician 2012; 58(10): 596-604. [acessado em 03 abr. 2013]. Disponível em http://www.ncbi.nlm. nih.gov/pmc/articles/PMC3470538/?tool =pubmed

19. Rios TA. Ética e competência. 20.ed. São Paulo: Cortez; 2011.

20. Missaka H, Ribeiro VMB. A preceptoria na formação médica: o que dizem os trabalhos nos congressos Brasileiros de educação médica 2007-2009. Rev bras educ med [online]. 2011; 35(3):303-310. [acessado em 22/03/2013]. Disponível em: http://www.scielo.br/pdf/rbem/v35n3/a02v35n3. pdf.

21. Shor I, Freire P. Medo e Ousadia: O Cotidiano do Professor. Tradução de Adriana Lopez. Revisão técnica de Lólio Lourenço de Oliveira. Rio de Janeiro: Paz e Terra; 1986.

\section{CONTRIBUIÇÃO DOS AUTORES}

Declaro que participei de forma suficiente na concepção e desenho da pesquisa que gerou o artigo "DESENVOLVIMENTO DISCENTE NO ESTÁGIO EM ESTRATÉGIA SAÚDE DA FAMÍLIA", bem como da análise e interpretação dos dados assim como da redação deste texto, para assumir a autoria e a responsabilidade pública pelo conteúdo deste artigo. Revi a versão final deste artigo e o aprovei para ser encaminhado à publicação. Declaro que nem o presente trabalho nem outro com conteúdo substancialmente semelhante de minha autoria foi publicado ou submetido à apreciação do Conselho Editorial de outra revista.

\section{CONFLITO DE INTERESSES}

Declarou não haver.

\section{ENDEREÇO PARA CORRESPONDÊNCIA}

João Klínio Cavalcante

Rua Hélio Pradines, 806 - apto.102

Ponta Verde - Maceió

CEP 57035-220 - AL

E-mail: joaoklinio@hotmail.com.br 